\title{
The predictive performance of infusion strategy nomogram based on a fluid kinetic model
}

\author{
Byung Moon Choi ${ }^{1}$, Myung Hwan Karm ${ }^{1}$, Kyeo Woon Jung ${ }^{1}$, \\ Young Goo $\mathrm{Yeo}^{2}$, and Kyu Taek Choi ${ }^{1}$ \\ ${ }^{1}$ Department of Anesthesiology and Pain Medicine, Asan Medical Center, University of Ulsan College of Medicine, \\ ${ }^{2}$ The College of Engineering Hanyang University, Seoul, Korea
}

\begin{abstract}
Background: In a previous study, fluid kinetic models were applied to describe the volume expansion of the fluid space by administration of crystalloid and colloid solutions. However, validation of the models were not performed, it is necessary to evaluate the predictive performance of these models in another population.

Methods: Ninety five consenting patients undergoing elective spinal surgery under general anesthesia were enrolled in this study. These patients were randomly assigned to three fluid groups i.e. Hartmann's solution (H group, $n=28$ ), Volu$\operatorname{ven}^{\circledR}$ (V group, $n=34$ ), and Hextend ${ }^{\circledR}$ (X group, $n=33$ ). After completion of their preparation for surgery, the patients received a loading and maintenance volume of each fluid predetermined by nomograms based on fluid pharmacokinetic models during the 60-minute use of an infusion pump. Arterial samples were obtained at preset intervals of $0,10,20$, and $30 \mathrm{~min}$ after fluid administration. The predictive performances of the fluid kinetic modes were evaluated using the fractional change of arterial hemoglobin. The relationship between blood-volume dilution and target dilution of body fluid space was also evaluated using regression analysis.

Results: A total of 194 hemoglobin measurements were used. The bias and inaccuracy of these models were -2.69 and 35.62 for the $\mathrm{H}$ group, -1.53 and 43.21 for the $\mathrm{V}$ group, and 9.05 and 41.82 for the $\mathrm{X}$ group, respectively. The bloodvolume dilution and target dilution of body-fluid space showed a significant linear relationship in each group $(\mathrm{P}<0.05)$. Conclusions: Based on the inaccuracy of predictive performance, the fluid-kinetic model for Hartmann's solution showed better performance than the other models.
\end{abstract}

Key Words: Fluid, Nomogram, Pharmacokinetics.

Corresponding author: Kyu Taek Choi, M.D., Ph.D.

Department of Anesthesiology and Pain Medicine, Asan Medical Center, University of Ulsan College of Medicine, 88, Olympic-ro 43gil, Songpa-gu, Seoul 138-736, Korea

Tel: 82-2-3010-3857, Fax: 82-2-3010-6790

E-mail: qtek@amc.seoul.kr

Received: March 31, 2014.

Revised: 1st, June 4, 2014; 2nd, August 13, 2014.

Accepted: September 4, 2014.

Korean J Anesthesiol 2015 April 68(2): 128-135

http://dx.doi.org/10.4097/kjae.2015.68.2.128

\section{Introduction}

It is important to maintain optimal blood volume of patients with infusion of crystalloid and/or colloid solutions. Inadequate fluid infusion can induce tachycardia, decreased blood pressure, and a decrease of perfusion pressure of major organs in surgical patients. As fluid overload may induce pneumonia and respiratory failure, impairment of cardiovascular and renal function, and coagulopathy, an adequate intravascular volume replacement is essential in the management of surgical patients

(c) This is an open-access article distributed under the terms of the Creative Commons Attribution Non-Commercial License (http://creativecommons.org/ licenses/by-nc/3.0/), which permits unrestricted non-commercial use, distribution, and reproduction in any medium, provided the original work is properly cited. 
[1-3]. Although static parameters, such as heart rate and blood pressure, are as essential as ever, recently, dynamic parameters, including stroke-volume variation and pulse-pressure variation, have assumed an important role in the management of fluid therapy during surgery $[4,5]$. However, these methods cannot quantify the change of blood volume induced by administration of crystalloid and colloid solutions. If we can characterize this in a mathematical manner, it may be helpful in order to maintain the appropriate volume status in surgical patients.

A Fluid kinetic model had been developed to describe change of the volume of the fluid space expanded by administration of fluids, which can illustrate nomograms to administer loading and maintenance volume of fluids for achieving target dilution of body fluid space (BFS) [6]. In a previous study, one-volume fluid kinetic models for various fluids were established in patients undergoing elective surgery under general anesthesia [7], however, validation of these models was not performed during the process of model building. To date, target-controlled fluid infusion has not been used in clinical situations, however, it may be used in the near future, even though innovative improvement of the fluid-kinetic model is required. Therefore, it may be necessary to evaluate the validity of kinetic models for various fluids.

The purpose of this study is to evaluate the predictive performance of fluid-kinetic models established in an earlier study in another patient population undergoing elective surgery under general anesthesia [7]. We also evaluated the relationship between blood-volume dilution and target dilution of BFS using regression analysis.

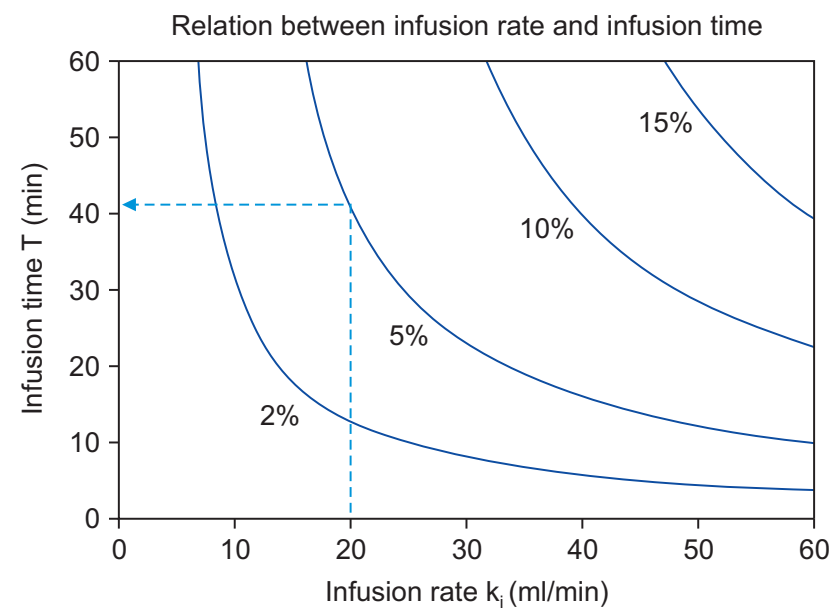

\section{Materials and Methods}

\section{Patient population}

After local ethics committee approval, written informed consent was obtained from 95 patients older than 18 years of age, ASA I-II, undergoing elective spinal surgery under general anesthesia. Those patients with diabetes mellitus, severe cardiopulmonary dysfunction, renal dysfunction were excluded (Table 1).

\section{Study procedure}

All patients fasted from midnight. Intravenous infusion of $0.9 \%$ saline with rate of $40 \mathrm{ml} / \mathrm{h}$ was started at 6 a.m. Once in the operating room, patients were monitored with electrocardiography, pulse oximetry, end-tidal carbon dioxide partial pressure. Anesthesia was induced with intravenous propofol $2 \mathrm{mg} / \mathrm{kg}$, effect-site target controlled infusion (TCI) of remifentanil (2 ng/ $\mathrm{ml})$. Rocuronium (1 mg/kg) I.V. was used to facilitate tracheal

Table 1. Demographic Data

\begin{tabular}{lccc}
\hline & $\begin{array}{c}\text { H group } \\
(\mathrm{n}=23)\end{array}$ & $\begin{array}{c}\text { V group } \\
(\mathrm{n}=28)\end{array}$ & $\begin{array}{c}\mathrm{X} \text { group } \\
(\mathrm{n}=28)\end{array}$ \\
\hline Age $(\mathrm{yr})$ & $60.2 \pm 8.5$ & $58.5 \pm 10.4$ & $55.3 \pm 14.4$ \\
Weight $(\mathrm{kg})$ & $62.4 \pm 10.2$ & $68.7 \pm 10.4$ & $63.2 \pm 9.3$ \\
Height $(\mathrm{m})$ & $1.61 \pm 0.08$ & $1.63 \pm 0.08$ & $1.66 \pm 0.07$ \\
Sex $(\mathrm{M} / \mathrm{F})$ & $12 / 11$ & $14 / 14$ & $13 / 15$ \\
\hline
\end{tabular}

Data are presented as mean $\pm \mathrm{SD}$ or count as appropriate. H: Hartmann's solution, V: Voluven ${ }^{\circledR}, \mathrm{X}:$ Hextend $^{\circledR}$.

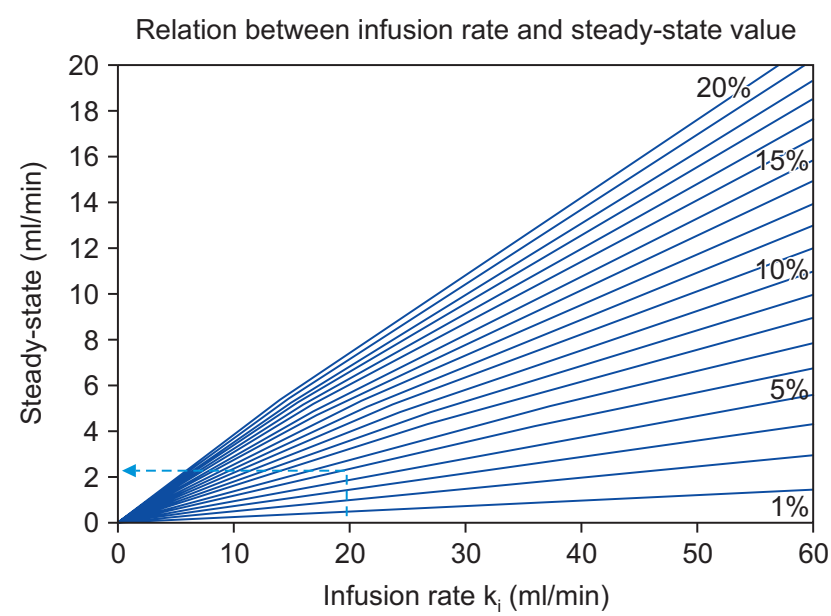

Fig. 1. Nomograms showing the relation between infusion time and, infusion rate (left) and steady state (right) for Hartmann's solution. The isobars (\%) show the predicted target dilution of body fluid space. When a patient receives Hartman's solution for target dilution of body fluid space, loading and maintenance volume are determined by using left and right panels, respectively. For example, in such a case of $5 \%$ dilution, loading volume of Hartmann's solution is infused at $20 \mathrm{ml} / \mathrm{min}$ for 42 minute, and then maintenance volume of Hartmann's solution is infused at $2.3 \mathrm{ml} / \mathrm{min} . k_{i}$ and steady state mean infusion rate for administration of loading volume and infusion rate for administration of maintenance volume, respectively (cited from Korean J Anesthesiol 2008; 54: 300-6). 
intubation. All participant's lungs were ventilated in volumecontrolled mode with tidal volume of $8-10 \mathrm{ml} / \mathrm{kg}$ at a frequency of $10 \mathrm{bpm}$ and zero end-expiratory pressure. Anesthesia was maintained with remifentanil TCI $(2 \mathrm{ng} / \mathrm{ml})$ and desflurane inhalation with $\mathrm{FIO}_{2} 0.5$ of $\mathrm{O}_{2}$ and air. Vasopressors were not used during the study period. To achieve and maintain stable fluid space dilution, 2, 3.5 and 5\% of target dilution, infusion rates for administration of loading and maintenance volumes were selected from nomograms for fluids (Figs. 1, 2 and 3) [7]. Infusion rate for loading volume in each patient was determined at the middle portion of nomograms (convex portion) except for both extremes. Target values of $2,3.5$, and $5 \%$ were chosen to evaluate the predictive performances of fluid kinetic models under consideration of patient safety during operation. These patients were randomly assigned to one of three fluid groups (Hartmann's solution [H group, $\mathrm{n}=23$ ], Voluven ${ }^{\circledR}$ [Fresenius Kabi, Bad Homburg, Germany, V group, $\mathrm{n}=28$ ], and Hextend ${ }^{\circledR}$ [Hospira, Lake Forest, IL, $\mathrm{X}$ group, $\mathrm{n}=28]$ ) in a sequence with one of the target dilution. After invasive arterial blood pressure monitoring was established, patients received each loading and maintenance volume of fluid predetermined by nomograms for 60 min using an infusion pump (Baxter Flo-Gard 6201, San Diego, CA).
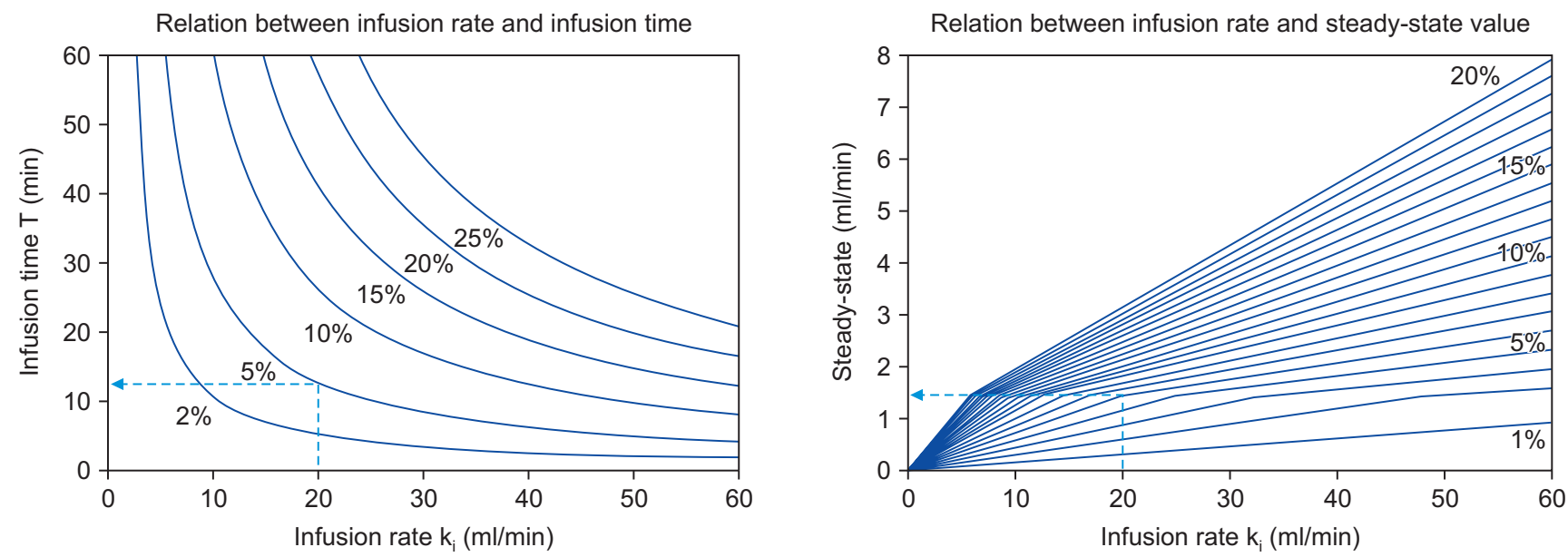

Fig. 2. Nomograms showing the relation between infusion time and, infusion rate (left) and steady state (right) for Voluven ${ }^{\circledR}$. The isobars (\%) show the predicted target dilution of body fluid space. When a patient receives Voluven ${ }^{\circledR}$ for target dilution of body fluid space, loading and maintenance volume are determined by using left and right panels, respectively. For example, in such a case of $5 \%$ dilution, loading volume of Voluven ${ }^{\circledR}$ is infused at $20 \mathrm{ml} /$ min for 13 minute, and then maintenance volume of Voluven ${ }^{\circledR}$ is infused at $1.4 \mathrm{ml} / \mathrm{min}$. $k_{i}$ and steady state mean infusion rate for administration of loading volume and infusion rate for administration of maintenance volume, respectively (cited from Korean J Anesthesiol 2008; 54: 300-6).
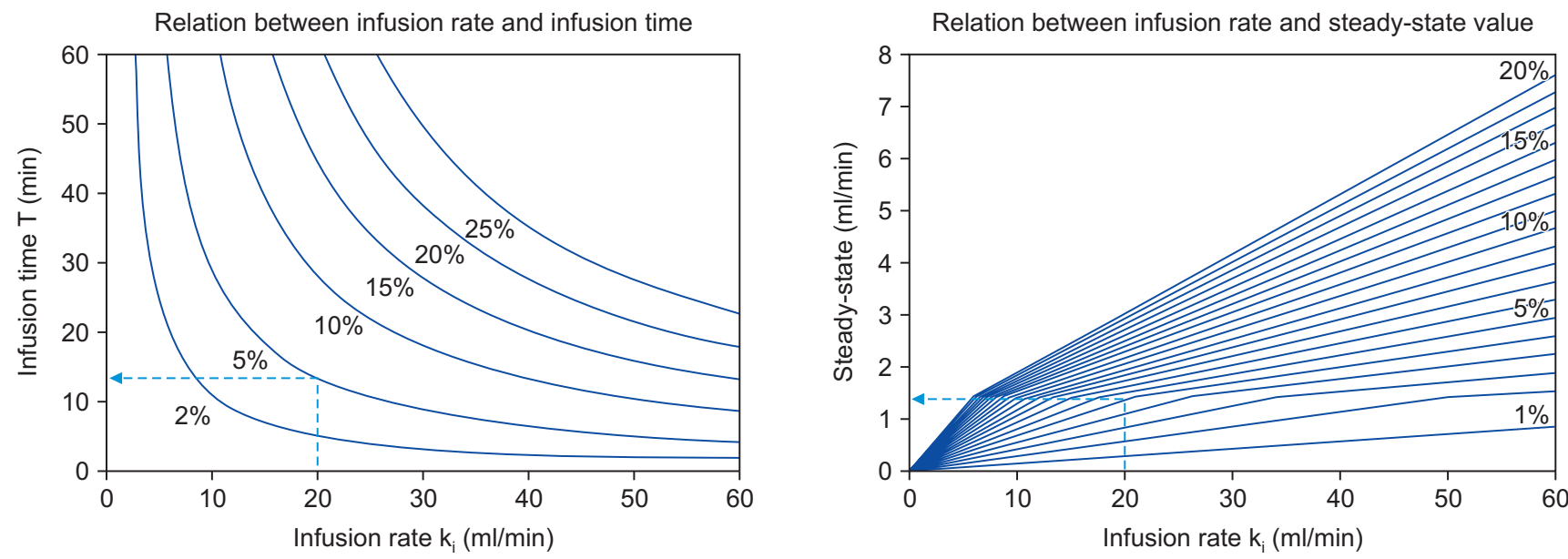

Fig. 3. Nomograms showing the relation between infusion time and, infusion rate (left) and steady state (right) for Hextend ${ }^{\circledR}$. The isobars (\%) show the predicted target dilution of body fluid space. When a patient receives Hextend ${ }^{\circledR}$ for target dilution of body fluid space, loading and maintenance volume are determined by using left and right panels, respectively. For example, in such a case of $5 \%$ dilution, loading volume of Hextend ${ }^{\circledR}$ is infused at $20 \mathrm{ml} /$ min for 13 minute, and then maintenance volume of Hextend ${ }^{\circledR}$ is infused at $1.3 \mathrm{ml} / \mathrm{min} . k_{i}$ and steady state mean infusion rate for administration of loading volume and infusion rate for administration of maintenance volume, respectively (cited from Korean J Anesthesiol 2008; 54: 300-6). 
Four arterial blood samples for hemoglobin measurement were obtained at preset intervals; before infusion, 10, 20 and $30 \mathrm{~min}$ after loading volume of fluid ( $\mathrm{t}-0, \mathrm{t}-10, \mathrm{t}-20, \mathrm{t}-30$, respectively). Hemoglobin was measured by Gem Premier 3000 (Instrumentation Laboratory, Lexington, MA, USA). Efforts to finish the study before surgical incision was carried out. If surgical incision began before completion of the study, further samplings were not gathered. Hemoglobin concentration higher than baseline value ( $\mathrm{t}-0)$ were discarded assuming sampling error. As a result, 22 samples for error, 25 samples for $\mathrm{t}-30$ ( 15 for $\mathrm{H}$ group, 6 for $\mathrm{V}$ group, 4 for $\mathrm{X}$ group) were missing and then, 61 samples from $\mathrm{H}$ group, 118 samples from $\mathrm{V}$ group and 98 samples from $\mathrm{X}$ group were collected and used to evaluate predictive performance of fluid kinetic models.

\section{Calculation of volume kinetics}

In this study, computer-generated nomograms for colloid solutions (Hextend ${ }^{\circledR}$, Voluven ${ }^{\circledR}$ ) and Hartmann's solution were used to infuse fluids. Nomograms were derived from onevolume, fluid-kinetic models [7]. The mathematical basis of the volume kinetics model has been described previously [7]. In short, fluid infused at the rate ki is distributed in BFS V, the sizes of which then increase to $\mathrm{v}$ at a later time $(\mathrm{t})$. Elimination occurs by virtue of a zero-order parameter $\mathrm{kb}$ (basal), and a first-order elimination rate constant, $\mathrm{kr}$ (urine). The volume change in $\mathrm{v}$ is described by the following differential equations:

$$
\begin{array}{ll}
\frac{d v}{d t}=k_{i}-k_{b}-k_{r} \frac{(v-V)}{V} & \text { (equation 1) } \\
\frac{(v(\mathrm{t})-V)}{V}=\frac{\left(\frac{H b_{o}}{H b_{t}}-1\right)}{1-H c t_{o}} &
\end{array}
$$

$V$ : target volume, $v$ : an expandable BFS, $H b_{o}$ : baseline hemoglobin concentration, $\mathrm{Hb}_{t}$ : hemoglobin concentration at time $\mathrm{t}$, $H_{c t} t_{0}$ : baseline hematocrit. The BFS dilution based on the model and blood volume dilutions $\left(\mathrm{H} b_{0} / H b_{t}-1\right)$ were calculated from fractional changes of arterial hemoglobin concentration. Characteristics of parameters were shown in Table 2.

Table 2. Characteristics of Fluid Kinetic Parameters Used for Nomograms

\begin{tabular}{lcll}
\hline \multicolumn{1}{c}{ Parameter } & \multicolumn{1}{c}{ H group } & \multicolumn{1}{c}{ V group } & \multicolumn{1}{c}{ X group } \\
\hline $\mathrm{kr}(\mathrm{male}, \mathrm{ml} / \mathrm{kg} / \mathrm{min})$ & $4.6(3.0-5.3)$ & $0.4(0.3-0.9)$ & $0.4(0.2-1.2)$ \\
$\mathrm{kr}($ female, $\mathrm{ml} / \mathrm{kg} / \mathrm{min})$ & $3.3(2.0-3.7)$ & $0.7(0.4-0.9)$ & $0.5(0.2-1.2)$ \\
$\mathrm{V}(\mathrm{male}, \mathrm{ml} / \mathrm{kg})$ & $153(135-239)$ & $72(68-92)$ & $85(79-93)$ \\
$\mathrm{V}($ female, $\mathrm{ml} / \mathrm{kg})$ & $173(150-232)$ & $67(49-91)$ & $65(55-110)$ \\
\hline
\end{tabular}

Data are presented as median (interquartile range). kr: elimination rate constant ( $\mathrm{ml} / \mathrm{kg} / \mathrm{min})$, V: expandable body fluid space ( $\mathrm{ml} / \mathrm{kg})$, H group: Hartmann's solution, V group: Voluven ${ }^{\circledR}$, X group: Hextend ${ }^{\circledR}$.

\section{Predictive performance}

As described in the earlier study [8], four parameters including bias, inaccuracy, divergence, and wobble, were used to evaluate the performance of fluid kinetic models.

First, for each measured BFS and target BFS, the performance error $(\mathrm{PE})$ of the ith individual was calculated as:

$$
\mathrm{PE}_{\mathrm{ij}}=\frac{\text { measured }_{\mathrm{ij}}-\text { predicted }_{\mathrm{ij}}}{\text { predicted }_{\mathrm{ij}}} \quad(\text { equation 2) }
$$

where predicted ${ }_{\mathrm{ij}}$ represents the target BFS at the $j$ th sampling point from the $i$ th patient, whereas measured $_{i j}$ is the measured BFS.

The first performance measure, a measure of bias, for the ith patient was reflected by calculating the median performance er$\operatorname{ror}\left(\mathrm{MDPE}_{\mathrm{i}}\right)$ :

$$
\left.M D P E_{i}=\operatorname{median}\left\{P E_{i j}, j=1, \ldots \ldots N_{i}\right\} \quad \text { (equation } 3\right)
$$

The inaccuracy, for the $i$ th patient, was reflected by calculating the median absolute performance error $\left(\mathrm{MDAPE}_{\mathrm{i}}\right)$ :

$$
M D A P E_{i}=\operatorname{median}\left\{\left|P E_{i j}\right|, j=1, \ldots \ldots . N_{i}\right\} \quad \text { (equation 4) }
$$

where $N_{i}$ is the number of PE in the $i$ th individual.

Divergence was calculated, for the $i$ th patient, as the slope acquired from the linear regression of that individual's the $\left|\mathrm{PE}_{\mathrm{ij}}\right| \mathrm{s}$ against time:

$$
\begin{aligned}
& \text { Divergence }_{i}(\% / h)= \\
& \qquad 60 \times \frac{\sum_{j=1}^{N_{i}}\left|P E_{i j}\right| \times t_{i j}-\left(\sum_{j=1}^{N_{i}} \mid P E_{i j}\right) \times\left(\sum_{j=1}^{N_{i}} t_{i j}\right) / N_{i}}{\sum_{j=1}^{N_{i}}\left(t_{i j}\right)^{2}-\left(\sum_{j=1}^{N_{i}} t_{i j}\right)^{2} / N_{i}} \quad \text { (equation 5) }
\end{aligned}
$$

where $t_{i j}$ is the time at which the corresponding $\mathrm{PE}_{\mathrm{ij}}$ was determined.

The fourth performance measure, Wobble ${ }_{\mathrm{i}}$, for the $i$ th individual was simply a measure of the variability of the $\mathrm{PE}_{\mathrm{ij}}$ in the $i$ th individual:

$$
\begin{aligned}
& \text { Wobble }_{i}= \text { median absolute deviation of }\left\{P E_{i j}, j=1, \ldots \ldots \ldots . . . N_{i}\right\} \\
& \text { from } M D P E_{i} \\
& \text { (equation 6) }
\end{aligned}
$$

\section{Relationship between blood volume dilution and target dilution of body fluid space}

Blood volume dilution at 2, 3.5, $5 \%$ of target dilution of body fluid space were calculated by the $\left(H b_{o} / H b_{t}-1\right)$ in each fluid 
group. Relationship between blood volume dilution and target dilution of body fluid space was analyzed in each group.

\section{Statistical analysis}

Population estimates of these performance measures was calculated by a pooled data approach (fit4NM 3.5.1, Eun-Kyung Lee and Gyu-Jeong Noh, http://www.fit4nm.org/download, last accessed: Oct 17, 2011) $[8,9]$. Comparison analysis was performed using non-parametric analysis (Kruskal-Wallis One Way Analysis of Variance on Ranks with Dunn's method), and regression analysis was achieved using a Pearson test or Spearman's rho test when necessary. Statistical analysis was performed with SPSS 12.0 statistics software (SPSS, Chicago, IL, USA). The level of significance was $\mathrm{P}<0.05$.

\section{Results}

The demographic data of patients enrolled in this study did not show significant differences between each group. Non per oral (NPO) time was not statistically different from three groups [median (25-75\%): 8.3 (8.1-10.6) in H group, 9.8 (8.1-12.9) in $\mathrm{V}$ group, 8.3 (8.1-11.1) in $\mathrm{X}$ group, $\mathrm{P}=0.144]$. A total of 194 arterial blood samples, except baseline samples, were used to determine the predictive performance of fluid kinetic models

Table 3. Total Volume and Infusion Rate of Fluids Infused by Guidance of Nomograms during $60 \mathrm{Min}$

\begin{tabular}{lllcc}
\hline \multicolumn{1}{c}{ Subgroup } & $\begin{array}{c}\text { Total } \\
\text { volume }(\mathrm{ml})\end{array}$ & $\begin{array}{c}\text { Loading } \\
\text { rate }(\mathrm{ml} / \mathrm{h})\end{array}$ & $\begin{array}{c}\text { Loading } \\
\text { time }(\mathrm{min})\end{array}$ & $\begin{array}{c}\text { Maintenance } \\
\text { rate }(\mathrm{ml} / \mathrm{h})\end{array}$ \\
\hline H 2\% $(\mathrm{n}=10)$ & $307 \pm 26$ & $1,020 \pm 253$ & $18 \pm 7$ & $44 \pm 7$ \\
H 3.5\% (n=8) & $639 \pm 49^{*}$ & $1,088 \pm 93$ & $34 \pm 5$ & $80 \pm 16$ \\
H 5\% (n=5) & $880 \pm 0^{*}$, & $1,200 \pm 0$ & $40 \pm 0$ & $240 \pm 0$ \\
V 2\% (n=9) & $121 \pm 2$ & $607 \pm 20$ & $10 \pm 0$ & $23 \pm 2$ \\
V 3.5\% (n=9) & $218 \pm 0^{*}$ & $900 \pm 0$ & $12 \pm 0$ & $48 \pm 0$ \\
V 5\% (n=10) & $304 \pm 15^{*,+}$ & $866 \pm 54$ & $18 \pm 1$ & $62 \pm 7$ \\
X 2\% (n=8) & $151 \pm 46$ & $600 \pm 0$ & $13 \pm 4$ & $23 \pm 4$ \\
X 3.5\% (n=10) & $209 \pm 10^{*}$ & $822 \pm 80$ & $13 \pm 2$ & $41 \pm 2$ \\
X 5\% (n=10) & $320 \pm 16^{*,+}$ & $794 \pm 142$ & $23 \pm 4$ & $50 \pm 14$ \\
\hline
\end{tabular}

Date are presented as mean \pm SD. H: Hartmann's solution, V: Voluven ${ }^{\circledR}$, $\mathrm{X}$ : Hextend ${ }^{\circledR}, 2,3.5,5 \%$ : target dilution of body fluid space, $* \mathrm{P}<0.05$ vs. $2 \%$ of subgroup in each fluid group, ${ }^{\dagger} \mathrm{P}<0.05$ vs. $3.5 \%$ of subgroup in each fluid group.

Table 4. Pooled Biases (median performance error, MDPE), Inaccuracies (median absolute performance error, MDAPE), Divergences, and Wobbles of the Target Dilution of Hartmann's Solution, Hextend ${ }^{\circledR}$, Voluven ${ }^{\circledR}$

\begin{tabular}{lccc}
\hline \multicolumn{1}{c}{ Parameter } & \multicolumn{1}{c}{ H group } & V group & X group \\
\hline Bias (\%) & $-2.69 *(-17.77$ to -3.69$)$ & $-1.53(-11.34$ to 4.11$)$ & $9.05^{*}(1.96$ to 18.36$)$ \\
Inaccuracy $(\%)$ & $35.62(29.26$ to 41.45$)$ & $43.21(37.29$ to 48.48$)$ & $41.82(39.08$ to 51.67$)$ \\
Divergence $(\% / h)$ & $-32.89(-)$ & $24.18(-)$ & $-12.23(-)$ \\
Wobble (\%) & $6.62(0.83$ to 9.80$)$ & $12.70(7.04$ to 18.12$)$ & $6.98(0.22$ to 13.69$)$ \\
\hline
\end{tabular}

Data are expressed as median $\left(95 \%\right.$ confidence interval). H: Hartmann's solution, V: Voluven ${ }^{\circledR}$, X: Hextend ${ }^{\circledR}$, $*$ Significant bias: $95 \%$ confidence interval of MDPE did not include zero.

A

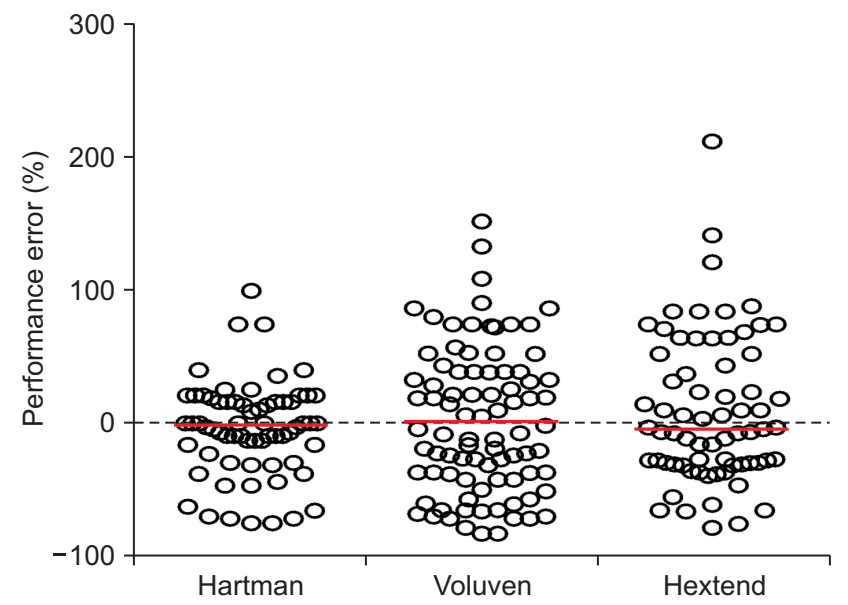

B

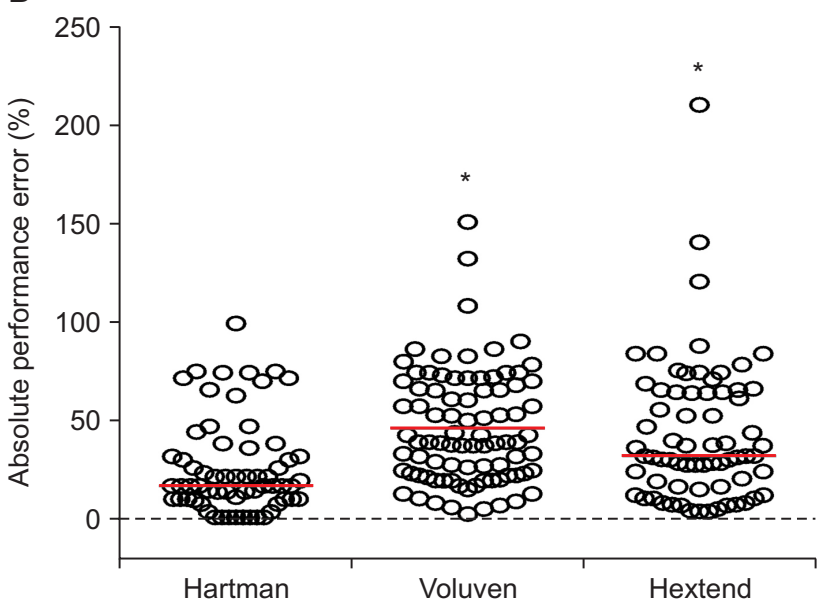

Fig. 4. Performance error and absolute performance error of target dilution for Hartmann's solution, Voluven ${ }^{\circledR}$, and Hextend ${ }^{\circledR}$. Empty circles $(\mathrm{O})$ and red horizontal lines indicate the performance error of each target dilution measurement and the median values, respectively. ${ }^{*} \mathrm{P}<0.05$ vs. Hartmann's solution. 
for crystalloid and colloid solutions. Total volume and infusion rate of fluids infused by guidance of nomograms during $60 \mathrm{~min}$ are demonstrated in Table 3. As we expected, larger fluid volume was required to achieve higher target dilution of BFS. The results of predictive performance of fluid kinetic models are depicted in Table 4. Significant bias was observed in fluid kinetic models of $\mathrm{H}$ and $\mathrm{X}$ groups. The fluid kinetic model for Hartmann's solution tends to over-predict target dilution of BFS, whereas that of Hextend ${ }^{\circledR}$ tends to under-predict. Performance error and absolute performance error of target dilution in fluid kinetic models are displayed in Fig. 4, where median absolute performance error of the fluid kinetic model for Hartmann's solution was lower than those of other models. This finding indicates that the fluid kinetic model for Hartmann's solution has better predictive performance compared with other models, which was accordance with results calculated by a pooled data approach (See the inaccuracy of Table 4). Fig. 5 indicates changes blood volume dilution according to target dilution of body fluid space, where blood volume dilution and target dilution of BFS showed a strong linear relationship in each group. Also, blood volume dilution of $\mathrm{H}$ group was two or three times greater than other groups in a target dilution of BFS.

\section{Discussion}

Over the last 20 years the concept of target-controlled infusion for hypnotics and opioid has considerably influenced the development and practice of intravenous anaesthesia [10]. A
A

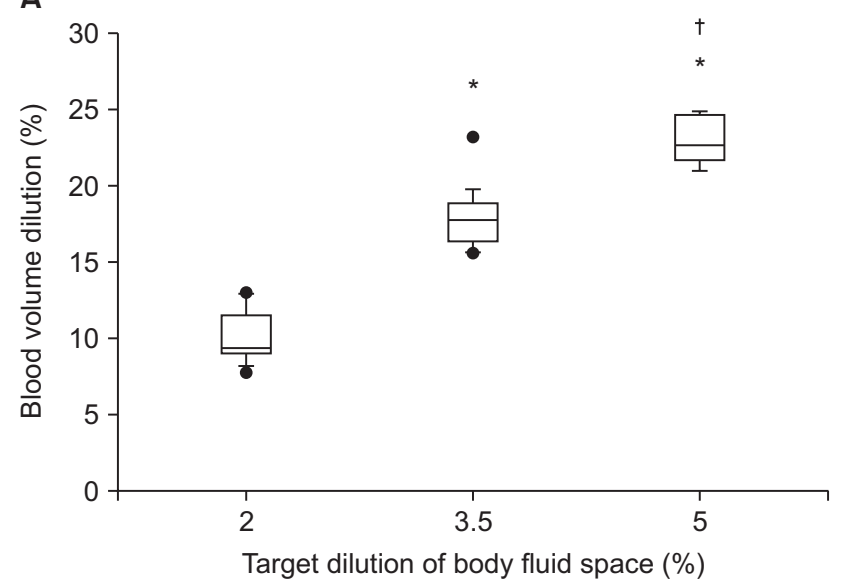

C

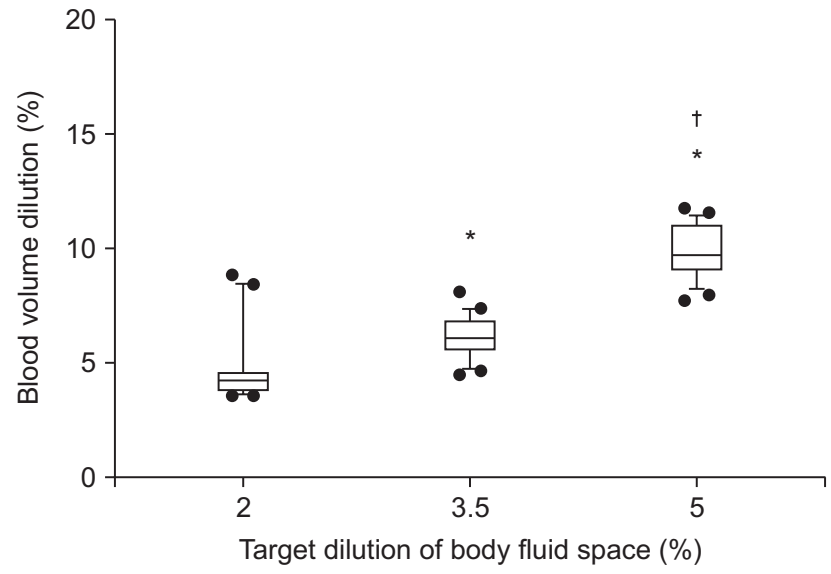

B

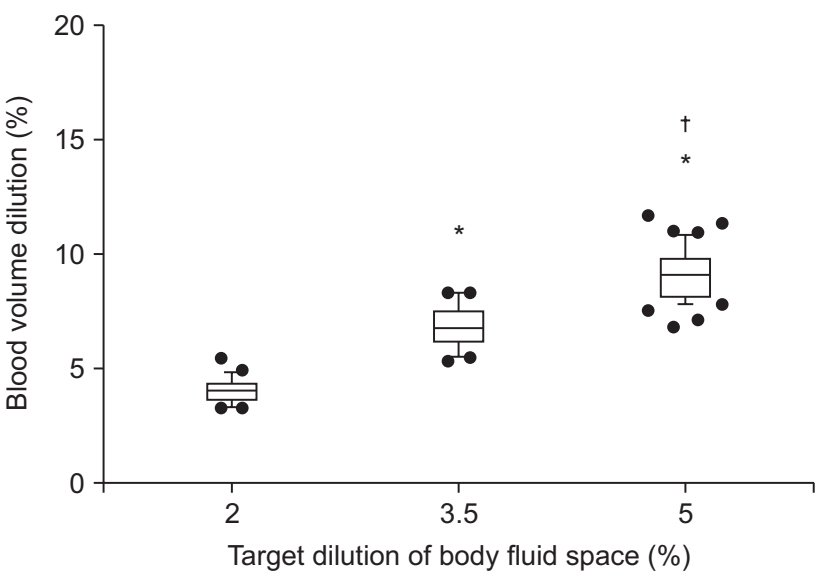

Fig. 5. Changes of blood volume dilution according to target dilution of body fluid space. (A) Hartmann's solution, (B) Voluven ${ }^{\circledR}$, (C) Hextend ${ }^{\circledR}$. The central box covers the interquartile range with the median indicated by the line within the box. The whiskers extend to the $10^{\text {th }}$ percentile and $90^{\text {th }}$ percentile values. More extreme values $(\bullet)$ are plotted individually. ${ }^{*} \mathrm{P}<0.05$ vs. $2 \%$ target dilution of body fluid space, ${ }^{\dagger} \mathrm{P}<0.05 \mathrm{vs} .3 .5 \%$ target dilution of body fluid space. Target dilution of body fluid space (TD) shows statistically significant linear regression with blood volume dilution (BVD) in all groups. TD $=2.185+0.144 \times \mathrm{BVD}$ for Hartmann's solution ( $\mathrm{H}$ group, $\left.R^{2}=0.151, \mathrm{P}=0.01\right)$, $\mathrm{TD}=0.239+0.498 \times \mathrm{BVD}$ for Voluven ${ }^{\circledR}(\mathrm{V}$ group, $\left.R^{2}=0.835, \mathrm{P}<0.001\right), \mathrm{TD}=0.718+0.408 \times \mathrm{BVD}$ for Hextend ${ }^{\circledR}\left(\mathrm{X}\right.$ group, $\left.R^{2}=0.718, \mathrm{P}<0.001\right)$. Median (inter-quartile range) value of BVD for $\mathrm{H}$ group was 9.4 (9.0-11.4), $17.8(16.5-18.7)$ and $22.7(21.8-24.4) \%$ for $2,3.5$, and $5 \%$ of target dilution, respectively. Median (inter-quartile range) value of BVD for V group was 4.0 (3.7-4.3), 6.7 (6.2-7.5) and 9.1 (8.2-9.7) \% for 2, 3.5, and 5\% of target dilution, respectively. Median (inter-quartile range) value of BVD for X group was 4.2 (3.9-4.6), 6.1 (5.7-6.8) and $9.7(9.2-11.0) \%$ for 2, 3.5, and 5\% of target dilution, respectively. 
TCI system can induce and maintain target concentration of a drug using a pharmacokinetic model [11,12]. A fluid kinetic model for optimal fluid therapy using concept of pharmacokinetic model was suggested by Hahn et al. $[6,13]$. The model can estimate the volume and kinetics of fluid space by characterizing the distribution and elimination of the infused fluid [6]. Elimination of fluid occurs from a central BFS by two mechanisms, one consisting of baseline diuresis and evaporation $\left(k_{b}\right)$ and the other being a dilution-dependent mechanism governed by a constant $\left(k_{r}\right)$. In a previous study, the model demonstrated the volume effect of Hartmann's solution increases according to hypovolemic status by showing a reduction of the elimination rate constant [13].

In earlier studies, one-volume and two-volume fluid kinetic models for various fluids were established in surgical patients and healthy volunteers, respectively $[7,14]$. The two-volume fluid kinetic model describes the volume effect of infused fluids using expansion of a central and a peripheral BFS. While, the onevolume fluid kinetic model explains the volume effect using only a central BFS, without the assumption that fluid is transported to a peripheral BFS. Although a two-volume model is thought to be associated with a more physiological fluid model, one-volume model was sufficient to describe fractional dilution of hemoglobin [7]. This result may be explained by the fact that duration of sampling scheme for hemoglobin measurements was relatively short (the last sampling time was $60 \mathrm{~min}$ after administration of fluid) [7], which may be a reason to ignore distribution from a central BFS to a peripheral BFS. At the process of model building, a statistical test was also used to determine whether the onevolume or two-volume model should be selected. There was a report that one-volume model is appropriate to describe timeprofiles of hemoglobin dilution and applies more consistently when a colloid fluid is infused [15].

Target dilution of BFS and blood volume dilution and showed a linear relationship in each group (Fig. 5), which means that infusion of fluid induces dilution of blood volume. Also, blood volume dilution of $\mathrm{H}$ group was greater than other groups, which may be explained by the fact that patients in $\mathrm{H}$ group received two or three times more volume than other groups. It seems that arterial blood sampling was performed before occurrence of fluid shift from blood vessel to interstitial space.

To the best of our knowledge, this study will be a fist study to evaluate the predictive performance of fluid kinetic models for various fluids. So, the criteria for acceptable range of fluid kinetic models are currently unavailable. Pooled biases and inaccuracies in pharmacokinetic predictions of propofol were clinically acceptable $(<10-20 \%$ and approximately $20-30 \%$, respectively) [16-18]. Although results of this study did not meet the criteria for acceptable range of propofol pharmacokinetic model, it is a significance to suggest reference values for fluid kinetic models, regardless of whether it's suitable or not. Pooled inaccuracies in three groups showed worse prediction of fluid kinetic models and divergences, index of how the resulting drug concentrations in a patient are affected by time, were high compared with those of propofol in adults ( -2 to $13.2 \% / h$ ) [17]. These results were attributed by the infusion method (loading volume, followed by maintenance volume). In general, during target controlled infusion, pharmacokinetic parameters derived from administration of a bolus dose showed worse prediction than those derived from infusion data [19]. If same infusion rate will be applied to this study throughout sampling period, it may be a possibility to improve the value of divergence. For crystalloid fluid such as Hartmann's solution, the one-volume model typically applies because the urinary excretion is prompt [15]. This fact may explain the reason that MDAPE in H group was lower than those of other groups. Because sampling points within a patient were small, the value of wobble may be insufficient to evaluate variability of performance errors in this population.

There are three methods, two-stage method (TS), pooled data method (PD) and variance-weighted approach (VW), to evaluate the population estimate of performance errors [8]. TS, the most commonly used method to obtain population estimates, estimates the population measures by simply taking the average of the individual measures [8]. Simply averaging the individual performance measures together may induce overemphasis on the less accurate ones and an under-emphasis on the more accurate ones. Properly weighting may be necessary to produce more precise population estimates. One particularly straightforward method of assigning these weights is to simply use the number of measurements for an individual as that individual's weight (PD) [8]. A slightly more involved, but more accurate, method is to weight the individual estimates by the reciprocal of the variance of each of those estimates (VW) [8]. This is quite critical when there are large discrepancies in the sampling points from different individuals. In this study, results of three methods were similar and we had an experience to report performance error of TCI system using pooled data analysis [18].

There were some issues to be considered as limitations of this study. First, pharmacokinetic parameters of one-volume fluid kinetic models had a large inter-individual variability as depicted in Table 2, which may be a reason of worse prediction of models. If pharmacokinetic models include patient-specific covariates, such as weight, height, sex, individual fluid infusion would be possible by the guidance of individual nomograms, which may improve predictive performance of fluid kinetic models. Pharmacokinetic modeling based on the population approach using non-mixed effects modeling can overcome this drawback. Second, hemoglobin concentrations in the arterial blood were used to calculate dilution of blood volume with assumption that intravascular volume is changed directly in proportion to blood 
hemoglobin concentration. Although it is not a true physiologic condition, blood volume dilution calculated by the mass balance equation using hemoglobin concentrations was also used in previous articles [20,21]. Third, last sampling time was relatively short (30 min after start of fluid infusion). Actually, mean loading time was greater than $30 \mathrm{~min}$ at 2.5 and $5 \%$ target dilution in $\mathrm{H}$ group (Table 3), which indicates that blood samples were not obtained in maintenance period. This fact may influence comparison of the results of predictive performance between three fluid kinetic models.

In conclusion, we performed external validation of onevolume, fluid-kinetic models for various fluids for the first time. The fluid kinetic model for Hartmann's solution showed better performance than other models, from inaccuracy of predictive performance. However, these models cannot be applied in a clinical setting as this study demonstrates the incompleteness of fluid-kinetic models. Therefore, it would be necessary to build supplementary models for clinical application.

\section{References}

1. Arieff AI. Fatal postoperative pulmonary edema: pathogenesis and literature review. Chest 1999; 115: 1371-7.

2. Cousins MJ, Skowronski G, Plummer JL. Anaesthesia and the kidney. Anaesth Intensive Care 1983; 11: 292-320.

3. Chappell D, Jacob M, Hofmann-Kiefer K, Conzen P, Rehm M. A rational approach to perioperative fluid management. Anesthesiology 2008; 109: 723-40.

4. Zhang Z, Lu B, Sheng X, Jin N. Accuracy of stroke volume variation in predicting fluid responsiveness: a systematic review and metaanalysis. J Anesth 2011; 25: 904-16.

5. Cannesson M, Aboy M, Hofer CK, Rehman M. Pulse pressure variation: where are we today? J Clin Monit Comput 2011; 25: 45-56.

6. Ståhle L, Nilsson A, Hahn RG. Modelling the volume of expandable body fluid spaces during i.v. fluid therapy. Br J Anaesth 1997; 78: 13843.

7. Kang SJ, Choi KT, Lee JH, Lee DH. Assessment of fluid space after infusion of hartmann's solution and hydroxyethyl starch solution during general anesthesia. Korean J Anesthesiol 2008; 54: 300-6.

8. Varvel JR, Donoho DL, Shafer SL. Measuring the predictive performance of computer-controlled infusion pumps. J Pharmacokinet Biopharm 1992; 20: 63-94.

9. Choi BM, Bang JY, Jung KW, Lee JH, Bae HY, Noh GJ. The comparison of predictive performance in bispectral index prediction during target effect-site controlled infusion of propofol using different blood effect-site equilibration rate constants in the same pharmacokinetic model. Korean J Anesthesiol 2013; 65: 299-305.

10. Schraag S, Kreuer S, Bruhn J, Frenkel C, Albrecht S. Target-controlled infusion (TCI) - a concept with a future?: state-of-the-art, treatment recommendations and a look into the future. Anaesthesist 2008; 57: 223-30.

11. Schnider TW, Minto CF, Gambus PL, Andresen C, Goodale DB, Shafer SL, et al. The influence of method of administration and covariates on the pharmacokinetics of propofol in adult volunteers. Anesthesiology 1998; 88: 1170-82.

12. Minto CF, Schnider TW, Egan TD, Youngs E, Lemmens HJ, Gambus PL, et al. Influence of age and gender on the pharmacokinetics and pharmacodynamics of remifentanil. I. Model development. Anesthesiology 1997; 86: 10-23.

13. Drobin D, Hahn RG. Volume kinetics of Ringer's solution in hypovolemic volunteers. Anesthesiology 1999; 90: 81-91.

14. Lee EH, Lee JY, Yeo YG, Choi KT. Modelling the expandable body fluid space after i.v. fluid infusion. Korean J Anesthesiol 2006; 51: 36-43.

15. Hahn RG. The use of volume kinetics to optimize fluid therapy. J Trauma 2003; 54(5 Suppl): S155-8.

16. Fechner J, Albrecht S, Ihmsen H, Knoll R, Schwilden H, Schüttler J. Predictability and precision of "target-controlled infusion" (TCI) of propofol with the "Disoprifusor TCI" system. Anaesthesist 1998; 47: 663-8.

17. Glen JB, Servin F. Evaluation of the predictive performance of four pharmacokinetic models for propofol. Br J Anaesth 2009; 102: 626-32.

18. Lee SH, Park HW, Kim MJ, Noh MH, Yoon HS, Choi BM, et al. External validation of pharmacokinetic and pharmacodynamic models of microemulsion and long-chain triglyceride emulsion propofol in beagle dogs. J Vet Pharmacol Ther 2012; 35: 329-41.

19. Vuyk J, Engbers FH, Burm AG, Vletter AA, Bovill JG. Performance of computer-controlled infusion of propofol: an evaluation of five pharmacokinetic parameter sets. Anesth Analg 1995; 81: 1275-82.

20. Hedin A, Hahn RG. Volume expansion and plasma protein clearance during intravenous infusion of 5\% albumin and autologous plasma. Clin Sci (Lond) 2005; 108: 217-24.

21. Brauer KI, Svensén C, Hahn RG, Traber LD, Prough DS. Volume kinetic analysis of the distribution of $0.9 \%$ saline in conscious versus isoflurane-anesthetized sheep. Anesthesiology 2002; 96: 442-9. 